\title{
Differences between carbon budget estimates unravelled
}

\author{
Joeri Rogelj ${ }^{1,2 \star}$, Michiel Schaeffer ${ }^{3,4}$, Pierre Friedlingstein ${ }^{5}$, Nathan P. Gillett ${ }^{6}$, Detlef P. van Vuuren ${ }^{7,8}$, \\ Keywan Riahi ${ }^{1,9}$, Myles Allen ${ }^{10,11}$ and Reto Knutti
}

Several methods exist to estimate the cumulative carbon emissions that would keep global warming to below a given temperature limit. Here we review estimates reported by the IPCC and the recent literature, and discuss the reasons underlying their differences. The most scientifically robust number - the carbon budget for $\mathrm{CO}_{2}$-induced warming only - is also the least relevant for real-world policy. Including all greenhouse gases and using methods based on scenarios that avoid instead of exceed a given temperature limit results in lower carbon budgets. For a $>66 \%$ chance of limiting warming below the internationally agreed temperature limit of $2{ }^{\circ} \mathrm{C}$ relative to pre-industrial levels, the most appropriate carbon budget estimate is 590-1,240 $\mathrm{GtCO}_{2}$ from 2015 onwards. Variations within this range depend on the probability of staying below $2{ }^{\circ} \mathrm{C}$ and on end-of-century non- $\mathrm{CO}_{2}$ warming. Current $\mathrm{CO}_{2}$ emissions are about $40 \mathrm{GtCO}_{2} \mathrm{yr}^{-1}$, and global $\mathrm{CO}_{2}$ emissions thus have to be reduced urgently to keep within a $2^{\circ} \mathrm{C}$-compatible budget.

$\mathrm{T}$ he ultimate objective of international climate negotiations is to prevent dangerous anthropogenic interference with the climate system ${ }^{1}$. At the 2015 Paris Conference, this objective was further specified as limiting global-mean temperature increase to well below $2{ }^{\circ} \mathrm{C}$ relative to pre-industrial levels and pursuing further efforts for limiting temperature increase to below $1.5^{\circ} \mathrm{C}$ (ref. 2).

Over the past decade, a large body of literature has been published that shows that the maximum global-mean temperature increase as a result of $\mathrm{CO}_{2}$ emissions is nearly linearly proportional to the total cumulative carbon $\left(\mathrm{CO}_{2}\right)$ emissions ${ }^{3-11}$. Maximum warming is also influenced by the amount of non- $\mathrm{CO}_{2}$ forcing leading up to the time of the peak ${ }^{12-14}$. This has culminated in the most recent assessment of the IPCC in the form of several estimates of emission budgets compatible with limiting warming to below specific temperature limits. Here, we first explain the underlying scientific rationale for such budgets and then continue with a detailed account of the strengths and limitations of the various budgets reported in both the IPCC Fifth Assessment Report (AR5) and the recent literature, and of the differences between them.

\section{The purpose of budgets}

The IPCC AR5 Working Group I (WGI) report ${ }^{15}$ indicated that the total net cumulative emission of anthropogenic $\mathrm{CO}_{2}$ is the principal driver of long-term warming since pre-industrial times. Therefore, to limit the warming caused by $\mathrm{CO}_{2}$ emissions to below a given temperature threshold, cumulative $\mathrm{CO}_{2}$ emissions from all anthropogenic sources need to be capped to a specific amount, sometimes referred to as the carbon budget or quota (which, in the context of this Perspective, refers to global values and not to the emission allowances of single countries).
The near-linearity between peak global-mean temperature rise and cumulative $\mathrm{CO}_{2}$ emissions is the result of an incidental interplay of several compensating feedback processes in both the carbon cycle and the climate: the logarithmic relationship between atmospheric $\mathrm{CO}_{2}$ concentrations and radiative forcing, the decline of ocean heatuptake efficiency over time, as well as the changes in the airborne fraction of anthropogenic $\mathrm{CO}_{2}$ emissions ${ }^{15}$. This compensating relationship is robust over a range of $\mathrm{CO}_{2}$ emissions and over timescales of up to a few centuries, with very few exceptions ${ }^{16}$. Such a relationship is not generally shown for other anthropogenic radiatively active species. An approximate proportionality exists for other longlived greenhouse gases (GHGs) for warming during this century ${ }^{12}$, whereas for short-lived climate forcers the rate of emissions leading up to the time of peak warming is important ${ }^{12-14}$.

The unique characteristics of the Earth system's response to anthropogenic carbon emissions allow the definition of a quantity called the transient climate response to cumulative emissions of carbon (TCRE). TCRE is defined as global average surface temperature change per unit of total cumulative anthropogenic $\mathrm{CO}_{2}$ emissions, typically 1,000 PgC. In AR5, TCRE was assessed to be 'likely' to lie (that is, with greater than $66 \%$ probability ${ }^{17}$ ) between 0.8 to $2.5^{\circ} \mathrm{C}$ per $1,000 \mathrm{PgC}$ for cumulative $\mathrm{CO}_{2}$ emissions less than about 2,000 PgC and until the time at which temperature peaks.

The constancy of TCRE means that it can also be assessed for the real world by dividing an estimate of $\mathrm{CO}_{2}$-induced warming to date by an estimate of anthropogenic $\mathrm{CO}_{2}$ emissions ${ }^{5,10}$. Such an approach relies on a calculation of GHG-attributable warming using a regression of observed warming onto the simulated response to GHGs and other forcings, and an estimate of the ratio of $\mathrm{CO}_{2}$ to total GHG radiative forcing or temperature response. Alternatively TCRE may be

'ENE Program, International Institute for Applied Systems Analysis (IIASA) Schlossplatz 1, A-2361 Laxenburg, Austria. ${ }^{2}$ Institute for Atmospheric and Climate Science, ETH Zurich, Universitätstrasse 16, CH-8092 Zürich, Switzerland. ${ }^{3}$ Climate Analytics, Karl-Liebknechtstrasse 5, 10178 Berlin, Germany. ${ }^{4}$ Environmental Systems Analysis Group, Wageningen University and Research Centre, PO Box 47, 6700 AA Wageningen, the Netherlands. ${ }^{5} \mathrm{College}$ of Engineering, Mathematics and Physical Sciences, University of Exeter, Exeter EX4 4QF, UK. ${ }^{6}$ Canadian Centre for Climate Modelling and Analysis, Environment Canada, University of Victoria, PO Box 1700, STN CSC, Victoria, British Columbia V8W 2Y2, Canada. ${ }^{7 P B L}$ Netherlands Environmental Assessment Agency, PO Box 303, 3720 AH Bilthoven, the Netherlands. ${ }^{8}$ Copernicus Institute of Sustainable Development, Faculty of Geosciences, Utrecht University, Budapestlaan 4, 3584 CD Utrecht, the Netherlands. ${ }^{9} \mathrm{Graz}$ University of Technology, Inffeldgasse, A-8010 Graz, Austria. ${ }^{10} \mathrm{ECl}$, School of Geography and the Environment, University of Oxford, Oxford OX1 3QY, UK. "Department of Physics, University of Oxford, Parks Road, Oxford OX13PU, UK. *e-mail: rogelj@iiasa.ac.at 


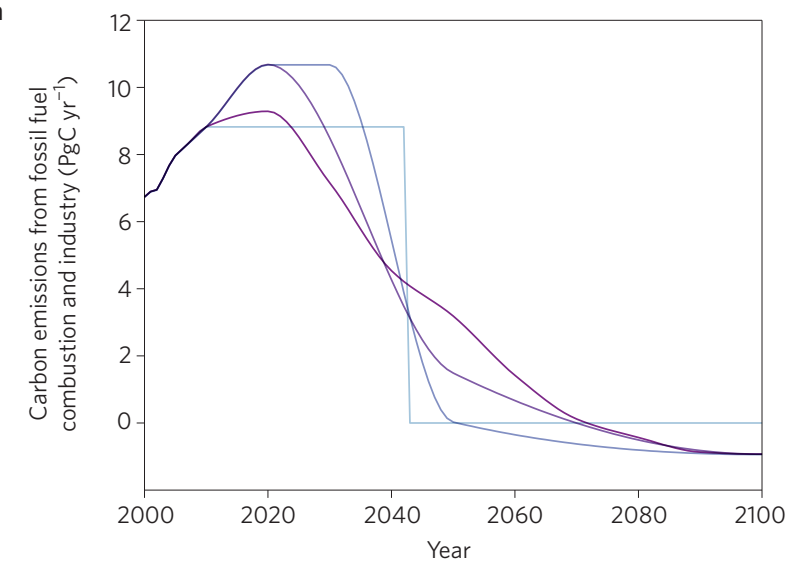

b

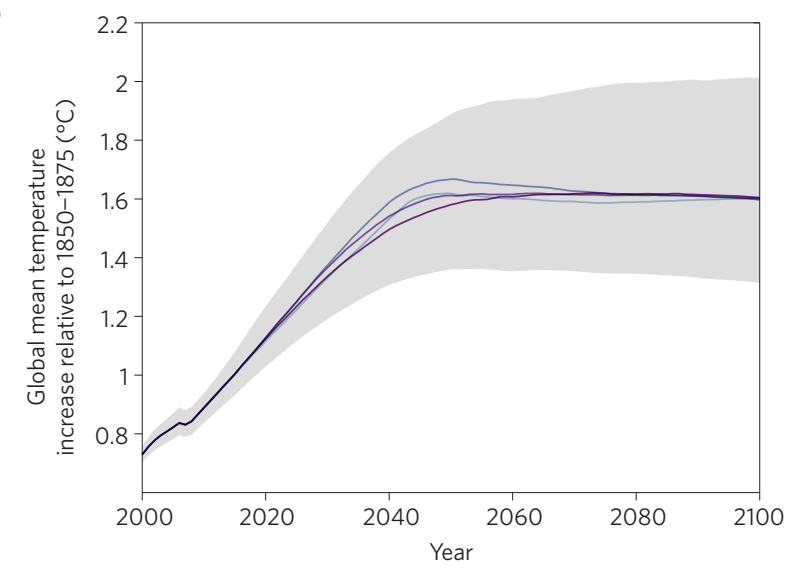

Figure 1 | Proportionality of global-mean temperature increase to cumulative emissions of $\mathrm{CO}_{2}$. $\mathbf{a}, \mathbf{b}$, Four $\mathrm{CO}_{2}$ emission pathways with identical cumulative carbon emissions over the twenty-first century (a) and their corresponding temperature projections (b). The grey area in $\mathbf{b}$ shows the central $66 \%$ uncertainty range of temperature projections around the thick purple line. Figure adapted with permission from ref. 15, (c) 2013 IPCC.

assessed from observations by applying observational constraints to the parameters of a simple carbon-cycle climate model ${ }^{7,8}$, and evaluating the ratio of warming to emissions for the constrained model.

For a carbon budget approach to make sense, TCRE must be reasonably independent of the pathway of emissions. Earlier studies have indeed shown that this is the case $e^{7,8,18,19}$, at least for peak warming and monotonously increasing cumulative carbon emissions. If a set carbon budget limit is exceeded, $\mathrm{CO}_{2}$ needs to be actively removed from the atmosphere afterwards ${ }^{20-22}$ to bring emissions back to within the budget. Figure 1 illustrates this path independency (even for moderate amounts of net negative $\mathrm{CO}_{2}$ emissions), and shows with the simple carbon cycle and climate model MAGICC ${ }^{7,23,24}$ that even with large variations in the pathway of $\mathrm{CO}_{2}$ emissions during the twenty-first century, the transient temperature paths as a function of cumulative $\mathrm{CO}_{2}$ emissions are very similar - a characteristic also found in other models ${ }^{18,25}$. Once all pathways achieve the same end-of-century cumulative $\mathrm{CO}_{2}$ emissions, the temperature projections are virtually identical (Fig. 1).

Given these considerations, carbon budgets are a useful guide for defining and characterizing the emissions pathways that limit warming to certain levels, such as $2{ }^{\circ} \mathrm{C}$ relative to pre-industrial levels.

\section{An abundance of carbon budgets}

Despite the simplicity of carbon budgets, many (often very different) estimates have been published. Here we provide an overview of how these budgets are defined and calculated.
Budget for $\mathrm{CO}_{2}$-induced warming only. The most direct application of TCRE is to derive cumulative carbon budgets consistent with limiting $\mathrm{CO}_{2}$-induced warming to below a specific temperature threshold. For instance, WGI indicates ${ }^{26}$ that limiting anthropogenic $\mathrm{CO}_{2}$-induced warming to below $2{ }^{\circ} \mathrm{C}$ relative to $1861-1880$ with an assessed probability of greater than $50 \%$ will require cumulative $\mathrm{CO}_{2}$ emissions from all anthropogenic sources since that period to stay approximately below 4,440 $\mathrm{GtCO}_{2}$. Alternatively, doing so with a greater than $66 \%$ probability would imply a $3,670 \mathrm{GtCO}_{2}$ budget. These values assume a normal distribution of which the standard deviation $(1 \sigma)$ range is given by the assessed likely TCRE range of 0.8 to $2.5^{\circ} \mathrm{C}$ per $1,000 \mathrm{PgC}$ (that is, about $3,670 \mathrm{GtCO}_{2}$ ), and make use of the near-linearity of the ratio of $\mathrm{CO}_{2}$-induced warming to cumulative $\mathrm{CO}_{2}$ emissions ${ }^{15}$.

Although this is the most robust translation of the TCRE concept into a cumulative carbon budget, it is at the same time also the least directly useful to policy-making. In the real world, non- $\mathrm{CO}_{2}$ forcing also plays a role, and its global-mean temperature effect is superimposed on the $\mathrm{CO}_{2}$-induced warming. A carbon budget derived from a TCRE-based estimate should thus not be used in isolation.

The near-linear relationship of TCRE does hence not necessarily apply to the ratio of total human-induced warming to cumulative carbon emissions (as might be suggested by Fig. SPM.10 in ref. 26). The latter relationship is scenario dependent, because, for example, the percentage contribution of non- $\mathrm{CO}_{2}$ climate drivers to total anthropogenic warming increases in the future in many scenarios. Therefore, to take into account the influence of non- $\mathrm{CO}_{2}$ forcing on carbon budgets, the TCRE-based approach can be extended using multi-gas emission scenarios. Multi-gas emission scenarios provide an internally consistent evolution over time of all radiatively active species of anthropogenic origin. They are often created with integrated assessment models (IAMs), which represent interactions within the global energy-economy-land system (for examples, see refs 27-29).

Threshold exceedance budgets. Here we define a straightforward methodology of extending TCRE-based carbon budgets for $\mathrm{CO}_{2}$ induced warming to budgets that also takes into account non- $\mathrm{CO}_{2}$ warming as 'threshold exceedance budgets' (TEBs) for multi-gas warming (Table 1).

This approach uses multiple realizations of the simulated response to a multi-gas emission scenario. These realizations can either be multi-model ensembles or perturbed parameter ensembles. An example of the former would be simulations of the Representative Concentration Pathways ${ }^{30,31}$ (RCPs) by Earth system models (ESMs) that were contributed to the Fifth Phase of the Coupled Model Intercomparison Project ${ }^{32}$ (CMIP5). An example of the latter would be the use of a simple climate model in a probabilistic setup ${ }^{7,23,24}$, as used in the assessments of the IPCC ${ }^{33-35}$ as well as in other recent studies $^{36-38}$. From such multi-model or perturbed parameter ensembles, the carbon budget is estimated at the time a specified share (for example, $50 \%$ or one-third) of realizations exceeds a given temperature limit (that is, $50 \%$ or two-thirds of the ensemble members remain below the limit; see orange scenario in Fig. 2).

The TEB approach was used by WGI for determining carbon budgets that account for non- $\mathrm{CO}_{2}$ forcing ${ }^{15}$. Applying this methodology to the CMIP5 RCP8.5 (ref. 39) simulations of ESMs ${ }^{10,40}$ and ESMs of intermediate complexity ${ }^{41}$ (EMICs), they found that compatible $\mathrm{CO}_{2}$ emissions since 1870 are about 3,010 $\mathrm{GtCO}_{2}$ and $2,900 \mathrm{GtCO}_{2}$ to limit warming to less than $2{ }^{\circ} \mathrm{C}$ since the period 1861-1880 in more than $50 \%$ and $66 \%$ of the available model runs, respectively. Other recent studies ${ }^{36}$ have used an extended version of this approach that computes TEBs based on perturbed parameter ensembles of a subset of scenarios from the IPCC AR5 Scenario Database (hosted at the International Institute for Applied Systems Analysis (IIASA); https://secure.iiasa.ac.at/web-apps/ene/AR5DB). 
Table 1 | Three different types of carbon budgets and their definitions.

\begin{tabular}{|c|c|c|}
\hline Carbon budget type & Abbreviation & Definition and description \\
\hline $\begin{array}{l}\text { Budget for } \mathrm{CO}_{2} \text {-induced } \\
\text { warming }\end{array}$ & $\mathrm{CO}_{2}$-only budget & $\begin{array}{l}\text { Amount of cumulative carbon emissions that are compatible with limiting warming to below a specific } \\
\text { temperature threshold with a given probability in the hypothetical case that } \mathrm{CO}_{2} \text { is the only source of } \\
\text { anthropogenic radiative forcing. This budget can be inferred from the assessed range of TCRE. }\end{array}$ \\
\hline $\begin{array}{l}\text { Threshold exceedance } \\
\text { budget }\end{array}$ & TEB & $\begin{array}{l}\text { Amount of cumulative carbon emissions at the time a specific temperature threshold is exceeded with a given } \\
\text { probability in a particular multi-gas emission scenarios. This budget thus takes into account the impact of } \\
\text { non- } \mathrm{CO}_{2} \text { warming at the time of exceeding the threshold of interest. }\end{array}$ \\
\hline $\begin{array}{l}\text { Threshold } \\
\text { avoidance budget }\end{array}$ & $\mathrm{TAB}$ & $\begin{array}{l}\text { Amount of cumulative carbon emissions over a given time period of a multi-gas emission scenario that limits } \\
\text { global-mean temperature increase to below a specific threshold with a given probability. This budget thus takes } \\
\text { into account the impact of non- } \mathrm{CO}_{2} \text { warming at peak global-mean warming, which is approximately the time } \\
\text { when global } \mathrm{CO}_{2} \text { emissions become zero and global-mean temperature is stabilized. }\end{array}$ \\
\hline
\end{tabular}

The results of a TEB approach are most useful if the warming due to non- $\mathrm{CO}_{2}$ forcing as a function of cumulative $\mathrm{CO}_{2}$ emissions is similar across scenarios, meaning that the conclusions are not strongly dependent on the scenario chosen. However, Fig. 3a shows that there is quite a large variation in non- $\mathrm{CO}_{2}$ forcing for a given level of cumulative $\mathrm{CO}_{2}$ emissions when looking at all scenarios available in the IPCC AR5 Scenario Database. Caution is therefore advised when deriving carbon budgets on the basis of one single multi-gas scenario (see below). Finally, the use of TEBs for limiting warming to below a given temperature limit assumes that non- $\mathrm{CO}_{2}$ warming never increases beyond the level it reached at the time the TEB was computed (Fig. 2). Non- $\mathrm{CO}_{2}$ forcing thus needs to be kept within limits over time.

Threshold avoidance budgets. Carbon budgets defined in the previous section are derived at the time a given scenario exceeds a specific temperature threshold or limit. A complementary approach is to consider multiple emission scenarios and evaluate carbon budgets for the subset of scenarios that avoids crossing such a threshold with a given probability. We name these budgets threshold avoidance budgets (TABs, Table 1). Because, by definition, such scenarios do not exceed the limit of interest at any specific point in time (with a given probability), a time horizon needs to be defined up to which a budget is computed. This time horizon can either be a predefined period, for example the 2011-2050 or the 2011-2100 period, or more variable in nature, for example the time period until peak warming (see yellow scenario in Fig. 2). Both of these approaches were used in AR5, and more sophisticated approaches based on the TAB methodology have been used in the literature ${ }^{7}$.

IPCC Working Group III (WGIII) computed TABs for the periods 2011-2050 and 2011-2100 by assessing probabilistic temperature projections in $2100^{34,35}$. For this, WGIII categorized a large number of scenarios on the basis of end-of-century $\mathrm{CO}_{2}$ equivalent concentrations. The reported TAB values - for example, in Table 6.3 in the WGIII Report ${ }^{35}$ or Table SPM.1 in the Synthesis Report $^{33,34}$ (SYR) - are therefore the result of an assessment of the exceedance probability outcomes found in each of the $\mathrm{CO}_{2}$ equivalent concentration categories. Alternatively, scenarios could have been categorized on the basis of median temperature, probabilities to limit warming to below a specific temperature limit, or even carbon budgets. For scenarios that limit end-of-century warming to below $2{ }^{\circ} \mathrm{C}$ with a likely probability, the WGIII assessment ${ }^{34}$ reports that the TABs in terms of cumulative $\mathrm{CO}_{2}$ emissions in the periods 2011-2050 and 2011-2100 are 150-1,300 $\mathrm{GtCO}_{2}$ and $630-1,180 \mathrm{GtCO}_{2}$, respectively.

In the IPCC $\mathrm{SYR}^{33}$, TABs are also computed on the basis of the scenarios available in the IPCC AR5 Scenario Database - see Table 2.2 in ref. 33 . However, the SYR categorizes scenarios directly based on their probability of keeping peak warming to below a specific temperature threshold $\left(1.5^{\circ} \mathrm{C}, 2^{\circ} \mathrm{C}\right.$ or $\left.3{ }^{\circ} \mathrm{C}\right)$ during the twenty-first century. For example, the IPCC SYR reports TABs for limiting warming to below $2{ }^{\circ} \mathrm{C}$ with at least $66 \%$ chance of 2,550-3,150 $\mathrm{GtCO}_{2}$ from 1870 until peak warming.

\section{The numbers compared}

To understand what the different approaches mean in terms of the actual values of carbon budgets, we compare the available budgets relating to the $2{ }^{\circ} \mathrm{C}$ limit. Table 2 provides an overview for all of the numbers discussed in this section, relative to two common base years (2011 and 2015). Taking into account that about $2,050 \mathrm{GtCO}_{2}$ (approximately $560 \mathrm{PgC}$ ) had already been emitted by the end of $2014^{36}$, a $\mathrm{CO}_{2}$-only budget approach would indicate that $1,620 \mathrm{GtCO}_{2}$ (or $440 \mathrm{PgC}$ ) remain to have a $>66 \%$ probability of limiting warming to below $2{ }^{\circ} \mathrm{C}$ relative to pre-industrial levels (here defined as the 1861-1880 period $\left.{ }^{26}\right)$. Using a TEB approach and assuming non- $\mathrm{CO}_{2}$ forcing as in RCP8.5, this amount is reduced to $850 \mathrm{GtCO}_{2}$ (or $230 \mathrm{PgC}$ ). When assessed with the latter approach, a $1,620 \mathrm{GtCO}_{2}$ budget would limit warming to below $2{ }^{\circ} \mathrm{C}$ in less than $33 \%$ of the available models ${ }^{42}$.

It is worth noting that the IPCC assessment of the $\mathrm{CO}_{2}$-only budget is based on an assessed uncertainty range of TCRE, drawing on many lines of evidence. The WGI numbers including non- $\mathrm{CO}_{2}$ forcing are based on CMIP5 simulations of the response to RCPs, which - although being a valid approach - provide a narrower scientific basis. At least for the four RCPs used by WGI, a similar warming as a function of cumulative $\mathrm{CO}_{2}$ emissions is found (see Fig. TFE. 8 in ref. 42), despite having different non- $\mathrm{CO}_{2}$ evolutions (Fig. 3a). This counterintuitive result is explained further below.

When extensively varying the non- $\mathrm{CO}_{2}$ assumptions for TEBs using a subset of baseline and weak mitigation scenarios from the IPCC AR5 Scenario Database (which all exceed the $2{ }^{\circ} \mathrm{C}$ limit), a range of 850-1,550 $\mathrm{GtCO}_{2}$ (5th-95th percentile range across all TEB scenarios, from 2015 onwards) is associated with limiting warming to below $2{ }^{\circ} \mathrm{C}$ with $66 \%$ probability ${ }^{36}$. The difference between this range and the $850 \mathrm{GtCO}_{2}$ number quoted above is, on the one hand, caused by the different modelling frameworks and, on the other hand, by the fact that the non- $\mathrm{CO}_{2}$ forcing evolution of RCP8.5 is situated amongst the highest percentiles of the non- $\mathrm{CO}_{2}$ forcing in other high-emission scenarios that exceed the $2{ }^{\circ} \mathrm{C}$ threshold (Fig. 3).

When considering TABs until peak warming, based on the stringent mitigation scenarios of the IPCC AR5 Scenario Database, a range of $590-1,240 \mathrm{GtCO}_{2}$ is found for limiting warming to below $2{ }^{\circ} \mathrm{C}$ with $>66 \%$ probability ${ }^{33}$ (10th-90th percentile range, as reported by WGIII, from 2015 onwards). Finally, for TABs calculated over the 2015-2100 period, an assessment of the stringent mitigation scenarios available in the IPCC AR5 Scenario Database and their temperature outcomes results in a range of 470-1,020 $\mathrm{GtCO}_{2}$ (10th-90th percentile range) for limiting warming to below $2{ }^{\circ} \mathrm{C}$ with a likely chance ${ }^{35}$.

In conclusion, moving from a $\mathrm{CO}_{2}$-only budget ${ }^{42}$ to a multi-gas multi-scenario TEB budget ${ }^{36}$ removes around $420 \mathrm{GtCO}_{2}$ (that is, the average of the $70-770 \mathrm{GtCO}_{2}$ range) from the $\mathrm{CO}_{2}$ budget from 


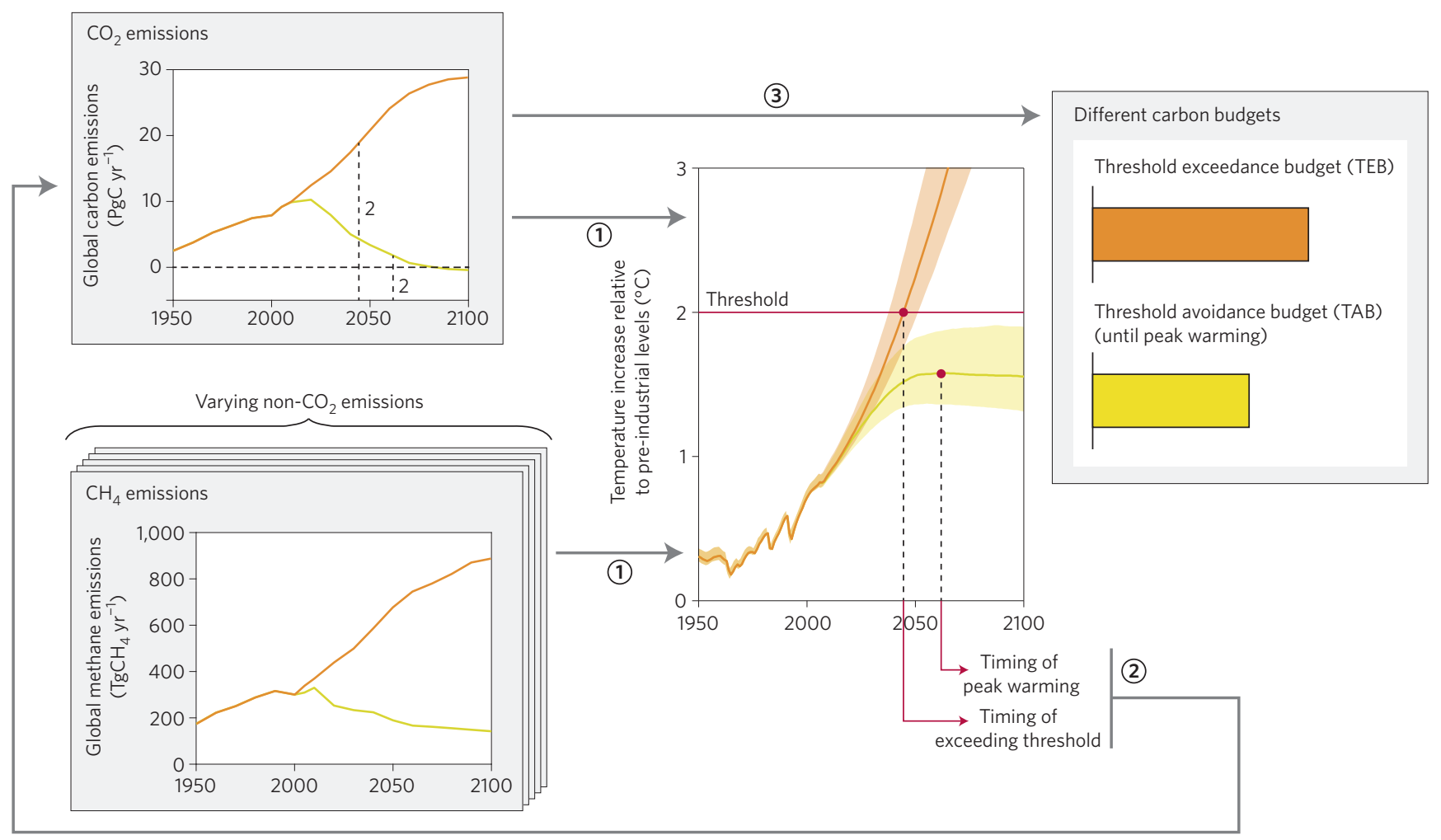

Figure $\mathbf{2}$ | An illustration of the methods for computing TEBs versus TABs. In the first step (arrows labelled 1), temperature outcomes are computed from multi-gas emission scenarios that either exceed (orange) or avoid (yellow) a given temperature threshold. Based on either the timing of exceeding the chosen threshold or the timing of peak warming, carbon budgets compatible with the chosen temperature threshold are computed in the second step (arrow labelled 2) by summing the carbon emissions of the underlying scenarios until the timing of exceeding the threshold or peak warming for the TEB or TAB (arrow labelled 3), respectively.

2015 onward for limiting warming to below $2{ }^{\circ} \mathrm{C}$ with $66 \%$ chance. Subsequently moving to a TAB budget until peak warming ${ }^{33}$ or over the 2015-2100 period ${ }^{35}$ and a $>66 \%$ chance would also remove about 260-310 $\mathrm{GtCO}_{2}$ and $380-530 \mathrm{GtCO}_{2}$, respectively. (Note that these values are illustrative as they are obtained by comparing ranges that are defined in different ways.)

The TAB range for limiting warming to below $2{ }^{\circ} \mathrm{C}$ with greater than $66 \%$ probability of $470-1,020 \mathrm{GtCO}_{2}$ for the $2015-2100$ period is thus 35 to $70 \%$ below what would have been inferred from a $\mathrm{CO}_{2}$ only budget with a TEB approach.

\section{Strengths and limitations}

The various approaches to computing carbon budgets each come with their respective strengths and limitations. Understanding what can lead to possible differences in budget estimates is critical to avoid misinterpretation of the numbers.

The budget type definition, the underlying data and modelling, the scenario selection, temperature response timescales and the accompanying pathway of $\mathrm{CO}_{2}$ and non- $\mathrm{CO}_{2}$ emissions are identified as possible key drivers of the difference between the various budget options discussed above.

That the budget type definition will have an influence on the resulting numbers is almost trivial. For example, when defining TABs from 2011 to 2100 instead of until peak warming, the cumulated net negative emissions that can be achieved until the end of the century will lead to consistently lower 2015-2100 TABs compared with TABs defined until peak warming levels. Negative emissions occur when $\mathrm{CO}_{2}$ is actively removed from, instead of emitted into, the atmosphere by human activities. For instance, for TABs compatible with limiting warming to below $2{ }^{\circ} \mathrm{C}$ with $>66 \%$ chance, the difference between TABs defined until peak warming and over the 2015-2100 period would be of the order of $120-220 \mathrm{GtCO}_{2}$. Furthermore, the budget type definition also influences other factors, such as scenario selection, whose impact on the carbon budget is explained in more detail below.

Underlying data and modelling. Some of the differences between the quantitative budgets estimates are simply driven by differences in the underlying data and models. In general, these differences apply to TEBs and TABs alike. For example, although the WGI $\mathrm{CO}_{2}$-only budget is based on the interpretation of an assessed uncertainty range, the other TEB and TAB budgets were computed either from CMIP5 RCP results (in the WGI report and the SYR) or from a simple climate model (MAGICC) in a probabilistic setup ${ }^{7,23,24}$ (in the WGIII report and the SYR).

Budget estimates can differ depending on whether a single-scenario multi-model ensemble is used (for example, all CMIP5 runs for RCP8.5) or alternatively a single-model multi-scenario perturbed parameter ensemble is used (for example, the IPCC AR5 WGIII approach, which uses MAGICC). The former approach allows us to use information from a wide range of the most sophisticated models and incorporate state-of-the-art Earth system interactions in the budget assessment. However, this approach comes at a high computational cost, resulting in only a limited ensemble of opportunity of model runs being available for any assessment. The latter method, on the other hand, uses a much simpler model, and hence comes with great computational efficiency, which allows for hundreds if not thousands of realizations per scenario. Thus variations in scenario assumptions on the pathways and evolution of non- $\mathrm{CO}_{2}$ forcing over time can be explored in more detail.

These differences in the underlying data and modelling can result in changes in the budget estimates. However, although a simple climate 

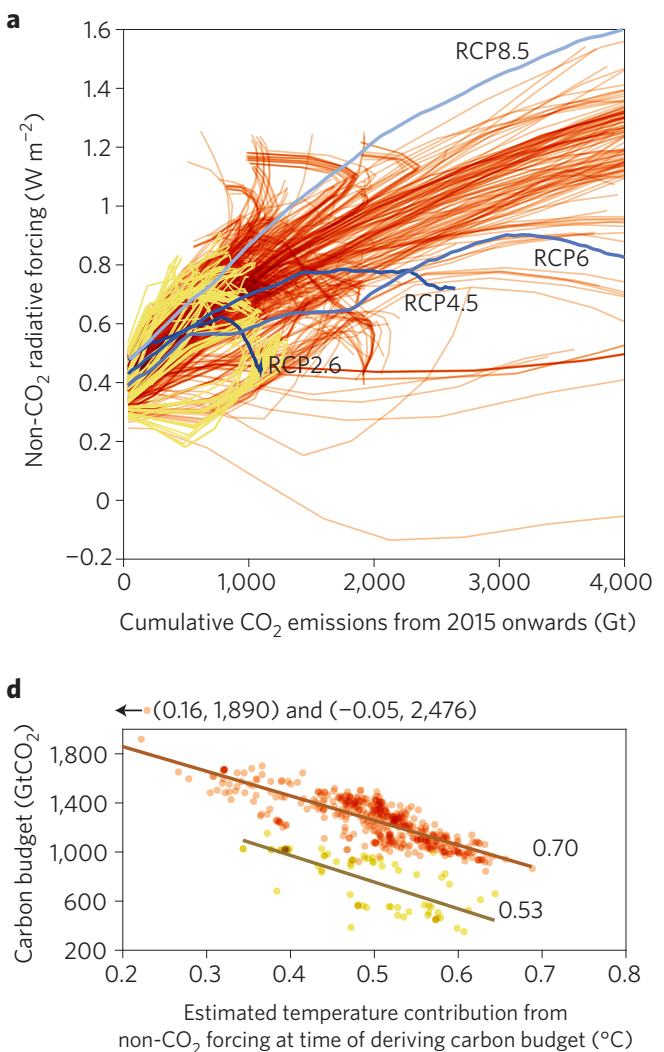
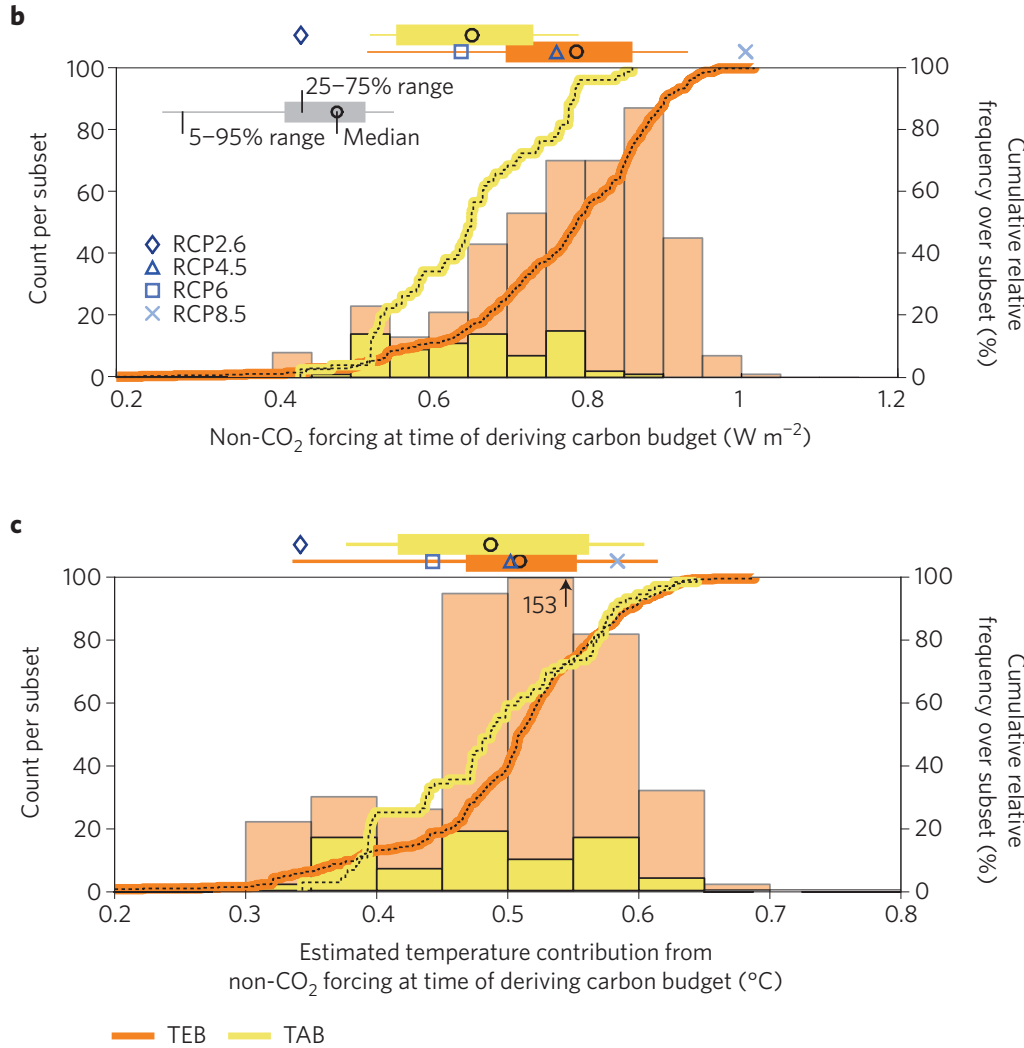

Figure 3 | Non- $\mathrm{CO}_{2}$ forcing and cumulative $\mathrm{CO}_{2}$ emissions. a, Non- $\mathrm{CO}_{2}$ forcing as a function of cumulative $\mathrm{CO}_{2}$ emissions from 2015 onwards for scenarios of the IPCC AR5 Scenario Database. Scenarios are split up into two subsets: those that limit warming to below $2{ }^{\circ} \mathrm{C}$ relative to pre-industrial levels with at least $66 \%$ probability (yellow, used for TABs), and those that lead to global-mean temperatures exceeding the $2^{\circ} \mathrm{C}$ limit with at least $34 \%$ (orange, used for TEBs). b. Distribution of non- $\mathrm{CO}_{2}$ forcing at the time point critical for deriving TEB (orange) and TAB (yellow) budgets, that is, the moment the $2{ }^{\circ} \mathrm{C}$ limit is exceeded for TEBs and peak warming for TABs. c, Distribution of the estimated temperature contribution from non- $\mathrm{CO}_{2}$ forcing at the same time point as in $\mathbf{b}$ (see Box 1). The four RCPs are also included for comparison. $\mathbf{d}$, Variation within the TEB and TAB budget subsets as a function of the estimated temperature contribution from non- $\mathrm{CO}_{2}$ forcing as in c. Numerical values in $\mathbf{d}$ are $R^{2}$ values for the two linear fits.

model does not provide the detail of ESMs, it can closely emulate their global-mean behaviour ${ }^{43}$ and can represent the uncertainties in carbon-cycle and climate response in line with the assessment of $\mathrm{AR} 5^{7,24,44}$. Of importance here is that the MAGICC setup applied in WGIII and the SYR is consistent with the CMIP5 ensemble for temperature projections and TCRE (Fig. 12.8 in ref. 15 and Fig. 6.12 in ref. 35). It is therefore expected that these differences are limited.

A final aspect related to the data and modelling is the interpretation of the nature of the uncertainties that accompany the various data. Uncertainty ranges can be the expression of a variety of underlying uncertainty sources ${ }^{45}$, and they can be interpreted in different ways. In the context of the quantification of carbon budgets, at least three kinds of uncertainty ranges can be distinguished: an uncertainty range resulting from an in-depth assessment of multiple lines of evidence (a so-called assessed uncertainty range); an uncertainty range emerging from a sophisticated statistical sampling of the parameter space; or an uncertainty range that represents the spread across an arbitrary collection of model results (a so-called ensemble of opportunity). Each of these uncertainty ranges can be interpreted in different ways, and they decline in robustness going from an assessed uncertainty range over targeted statistical approaches to ensembles of opportunities. These aspects thus also influence the robustness of any carbon budget estimates based on them. For example, the budget for $\mathrm{CO}_{2}$-induced warming from WGI is derived from an assessed uncertainty range, whereas the WGI budgets that also take into account non- $\mathrm{CO}_{2}$ forcing are based on an ensemble of opportunity, which makes them much less robust (see also Technical Focus Element 8 in ref. 42).
Scenario selection. Applying the definitions of TEBs and TABs to a large scenario ensemble for the assessment of $\mathrm{CO}_{2}$ budgets in line with a particular temperature limit results in the selection of two disjoint subsets of emission scenarios: a subset of baseline and weak mitigation scenarios that exceed the temperature limit with a given probability in the case of TEB budgets and a disjoint subset of more stringent to very stringent mitigation scenarios that all keep warming to below the specified temperature limit with a given probability in the case of TAB budgets.

\section{Box 1 | Non- $\mathrm{CO}_{2}$ temperature contributions.}

The estimated temperature contributions of non- $\mathrm{CO}_{2}$ forcing, shown in Fig. 3c, are derived by the following equation, as described in the Supplementary Material to the WGI chapter on 'Anthropogenic and Natural Radiative Forcing'53 (equation 8.SM.13).

$$
R_{T}(t)=\sum_{j=1}^{M} \frac{c_{j}}{d_{j}} \exp \left(-\frac{t}{d_{j}}\right)
$$

where $R_{T}$ is the climate response to a unit of forcing, $c_{j}$ the component of the climate sensitivity, $d_{j}$ the response times, and $t$ the time. For the two-term approximation $(M=2)$ presented by ref. 54, values of $c_{1}, c_{2}, d_{1}$, and $d_{2}$ are taken from table 8.SM.9 in ref. 53. This estimate is to be considered an illustrative approximation of the temperature effect of non- $\mathrm{CO}_{2}$ forcing. 


\begin{tabular}{|c|c|c|c|c|}
\hline Source & Type & Specification & $\begin{array}{l}\text { Value from } 2011 \\
\left(\mathrm{GtCO}_{2}\right)\end{array}$ & $\begin{array}{l}\text { Value from } 2015 \\
\left(\mathrm{GtCO}_{2}\right)\end{array}$ \\
\hline IPCC AR5 WGI26 & TEB & $\begin{array}{l}\text { To limit warming to less than } 2{ }^{\circ} \mathrm{C} \text { since the period } 1861-1880 \text { in more than } 66 \% \text { (or } \\
50 \% \text { ) of the model runs when accounting for the non- } \mathrm{CO}_{2} \text { forcing as in the RCP } 8.5 \\
\text { scenario }\end{array}$ & 1,010 (or 1,120 ) & 850 (or 960) \\
\hline IPCC AR5 WGI||35 & $\mathrm{TAB}$ & $\begin{array}{l}\text { To limit warming in } 2100 \text { to below } 2^{\circ} \mathrm{C} \text { since } 1850-1900 \text { with a 'likely' (>66\%) } \\
\text { probability, accounting for the non- } \mathrm{CO}_{2} \text { forcing as spanned by the subset of stringent } \\
\text { mitigation scenarios in the IPCC AR5 Scenario Database*. (10-90\% range over } \\
\text { scenarios in IPCC WGIII scenario category 1) }\end{array}$ & 630 to 1,180 & 470 to 1,020 \\
\hline IPCC AR5 WGIII35 & $\mathrm{TAB}$ & $\begin{array}{l}\text { To limit warming in } 2100 \text { to less than } 2^{\circ} \mathrm{C} \text { since } 1850-1900 \text { with a 'more likely than } \\
\text { not' (>50\%) probability, accounting for the non- } \mathrm{CO}_{2} \text { forcing as spanned by the subset } \\
\text { of stringent mitigation scenarios in the IPCC AR5 Scenario Database*. (10-90\% } \\
\text { range over scenarios in IPCC AR5 scenario category II without overshoot) }\end{array}$ & 960 to 1,430 & 800 to 1,270 \\
\hline IPCC AR5 SYR & $\mathrm{TAB}$ & $\begin{array}{l}\text { To limit warming to below } 2^{\circ} \mathrm{C} \text { since } 1861-1880 \text { with } 66-100 \% \text { probability, } \\
\text { accounting for the non- } \mathrm{CO}_{2} \text { forcing as spanned by the subset of stringent mitigation } \\
\text { scenarios in the IPCC AR5 Scenario Database. (10-90\% range) }\end{array}$ & 750 to 1,400 & 590 to 1,240 \\
\hline IPCC AR5 SYR ${ }^{33}$ & $\mathrm{TAB}$ & $\begin{array}{l}\text { To limit warming to below } 2^{\circ} \mathrm{C} \text { since } 1861-1880 \text { with } 50-66 \% \text { probability, accounting } \\
\text { for the non- } \mathrm{CO}_{2} \text { forcing as spanned by the subset of stringent mitigation scenarios in } \\
\text { the IPCC AR5 Scenario Database. ( } 10-90 \% \text { range) }\end{array}$ & 1,150 to 1,400 & 990 to 1,240 \\
\hline Friedlingstein et al. ${ }^{36}$ & TEB & $\begin{array}{l}\text { To limit warming to less than } 2^{\circ} \mathrm{C} \text { since } 1850-1900 \text { with a } 66 \% \text { probability, } \\
\text { accounting for the non- } \mathrm{CO}_{2} \text { forcing as spanned by the subset of baseline and weak } \\
\text { mitigation scenarios in the IPCC AR5 Scenario Database*. (5-95\% range) }\end{array}$ & $\begin{array}{l}1,310(1,010 \text { to } \\
1,710)\end{array}$ & $\begin{array}{l}1,150 \text { (850 to } \\
1,550)\end{array}$ \\
\hline Friedlingstein et al. ${ }^{36}$ & TEB & $\begin{array}{l}\text { To limit warming to less than } 2^{\circ} \mathrm{C} \text { since } 1850-1900 \text { with a } 50 \% \text { probability, } \\
\text { accounting for the non- } \mathrm{CO}_{2} \text { forcing as spanned by the subset of baseline and weak } \\
\text { mitigation scenarios in the IPCC AR5 Scenario Database*. (5-95\% range) }\end{array}$ & $\begin{array}{l}1,610(1,210 \text { to } \\
2,010)\end{array}$ & $\begin{array}{l}1,450(1,050 \text { to } \\
1,850)\end{array}$ \\
\hline
\end{tabular}

$1,890 \mathrm{GtCO}_{2}$ were already emitted by 2011 , and about $2,050 \mathrm{GtCO}_{2}$ by 2015 . All values are rounded to the nearest 10 . Budget types are defined in Table 1. ${ }^{\star}$ The temperature difference between $1861-1880$ and $1850-1900$ is $0.02^{\circ} \mathrm{C}$, based on ref. 55 .

A first implication of the use of these disjoint scenario sets results from only very few scenarios being available that have, for example, precisely a $66 \%$ probability for limiting warming to below a given temperature threshold. Although TEBs are consistently computed for each scenario at the time a scenario exceeds a temperature limit with a given probability, the value of TABs is further driven by the choice of the range of probabilities that is used to select appropriate TAB scenarios. For example, the IPCC SYR selected all scenarios that have a 66 to $100 \%$ probability of limiting warming to below a given threshold (compared with exactly $66 \%$ for TEBs). This resulted in an average probability of staying below $2{ }^{\circ} \mathrm{C}$ across the subset of TAB scenarios that comply with the above-mentioned selection criterion of about $75 \%$. This can explain about one-third to half of the $260-310 \mathrm{GtCO}_{2}$ difference between the TEB estimates from Friedlingstein et al. ${ }^{36}$ and the IPCC SYR TAB estimates. Moreover, for some temperature levels, for example around $3{ }^{\circ} \mathrm{C}$, the scenarios available in the IPCC AR5 Scenario Database do not sample the possible range extensively, which can lead to further biases in the numbers obtained.

Temperature response timescales. A second aspect that is different in the disjoint scenario subsets are the $\mathrm{CO}_{2}$ emission pathways and hence the annual $\mathrm{CO}_{2}$ emissions at the time the compatible carbon budget is derived. In the TAB subset, $\mathrm{CO}_{2}$ emissions will typically approach zero or become negative to stabilize global temperatures, and will thus be very low at the time of maximum warming during the twenty-first century. In the TEB subset this is not the case. Because of the timescales of $\mathrm{CO}_{2}$-induced warming ${ }^{46,47}$ this leads to differences in the carbon budget estimates.
Recent research indicates that, at current emission rates, maximum $\mathrm{CO}_{2}$-induced warming only occurs about a decade after a $\mathrm{CO}_{2}$ emission ${ }^{46,47}$. Thus, even in a $\mathrm{CO}_{2}$-only world, TABs and TEBs with complementary probabilities (for example, a $66 \%$ probability to limit warming below $2{ }^{\circ} \mathrm{C}$ and a $34 \%$ probability of exceeding $2{ }^{\circ} \mathrm{C}$ ) would not be entirely identical. In case of the TEB approach, the maximum warming of the $\mathrm{CO}_{2}$ emissions of the last decade before the temperature limit was exceeded has possibly not yet fully occurred. In a TAB approach the emissions in the last decade would be significantly lower, if not zero, and this would allow a much larger fraction of the warming to already be realized. The TEB approach thus leads to a consistent overestimate of the $\mathrm{CO}_{2}$ budget compatible with a given temperature limit, whereas this is not the case with the TAB approach. At least one-third of the approximately $260-310 \mathrm{GtCO}_{2}$ difference between the TEB estimates from Friedlingstein et al. ${ }^{36}$ and the IPCC SYR TAB estimates can be explained by accounting for the approximately one decade delay between $\mathrm{CO}_{2}$ emissions and their maximum warming.

Non- $\mathrm{CO}_{2}$ warming contribution. A third and last aspect that differs between the two disjoint TEB and TAB scenario subsets is the mixture of $\mathrm{CO}_{2}$ and non- $\mathrm{CO}_{2}$ forcers. This mixture differs over time and therefore, depending on when the compatible carbon budget is determined, the TABs and TEBs are derived under possibly very different non- $\mathrm{CO}_{2}$ forcing (Fig. 3b). The relationship between $\mathrm{CO}_{2}$ emissions and non- $\mathrm{CO}_{2}$ forcing is complex, as it covers the total non- $\mathrm{CO}_{2}$ forcing that results from both positive and negative climate forcers. Climate policy influences these non- $\mathrm{CO}_{2}$ forcers 
both directly (via abatement measures) and indirectly (via changes induced in the energy system), and this is captured in different ways in IAMs. For example, stabilizing and peaking global temperatures requires global $\mathrm{CO}_{2}$ emissions to be reduced to close to net zero. Such very low $\mathrm{CO}_{2}$ emissions are achieved through a fundamental transformation of the global energy-economy-land system ${ }^{35}$, which in turn leads to changes in non- $\mathrm{CO}_{2}$ emissions because of the phaseout of common sources of $\mathrm{CO}_{2}$ and non- $\mathrm{CO}_{2}$ emissions ${ }^{14,48}$. This can lead to important differences in non- $\mathrm{CO}_{2}$ forcing as a function of total cumulative $\mathrm{CO}_{2}$ emissions (Fig. 3a). Figure $3 \mathrm{~b}$ shows that median non- $\mathrm{CO}_{2}$ forcing at the time that is of importance for deriving the carbon budget (that is, the time of exceedance for TEBs, and peak warming for TABs) is about $0.2 \mathrm{~W} \mathrm{~m}^{-2}$ higher in the subset of scenarios used for TEBs compared with the subset used for TABs.

However, the non- $\mathrm{CO}_{2}$ forcing at either peak warming or the time of exceeding a given temperature threshold does not tell the entire story. When estimating the actual non- $\mathrm{CO}_{2}$-induced warming at these time points of interest (see Box 1), very little difference can be found between the TEB and TAB scenario subsets (Fig. 3c). This suggests that when a sufficiently large scenario sample is available, variations in non- $\mathrm{CO}_{2}$ forcing cannot be used to explain the variations between TEB and TAB estimates for limiting warming to below $2{ }^{\circ} \mathrm{C}$. The precise influence of this difference on the carbon budgets has not been quantified.

Incidentally, this feature is not obviously visible when looking at the four RCPs only, because both the lowest, RCP2.6, and the highest, $\mathrm{RCP} 8.5$, are outliers in terms of non- $\mathrm{CO}_{2}$ warming, at opposite sides of the scenario distribution (Fig. 3b,c).

Finally, although non- $\mathrm{CO}_{2}$ forcing does not fully explain the variations between TEB and TAB estimates, it plays an important role for the variation within the TEB and TAB subsets. Figure $3 \mathrm{~d}$ shows that respectively $70 \%$ and $50 \%$ of the variance within the TEB and $\mathrm{TAB}$ subsets can be explained by non- $\mathrm{CO}_{2}$ warming at the time of determining the carbon budget.

Future non- $\mathrm{CO}_{2}$ warming under stringent mitigation remains nonetheless very uncertain at present. Its magnitude will depend on the extent to which society will be successful in bringing about assumed future improvements in agricultural yields and practices or dietary changes ${ }^{49}$, amongst many other factors. These are very uncertain. Furthermore, how much non- $\mathrm{CO}_{2}$ forcing is reduced compared with $\mathrm{CO}_{2}$ depends on the relative weight that is given to $\mathrm{CO}_{2}$ and non- $\mathrm{CO}_{2}$ emissions in mitigation scenarios, and also on other mitigation choices ${ }^{50}$. These weights are mostly constant in IAMs (for example, by using global warming potentials as a fixed exchange rate), but can also change over time and depend on the question posed.

Air pollution controls can influence the rate of near-term warming and, depending on the precise mix of air pollutants that is reduced by air pollution controls, non- $\mathrm{CO}_{2}$ warming can be increased, decreased or stay constant ${ }^{14}$. The estimated effect of air pollution controls on carbon budgets, in particular on TABs, is very small $^{51}$. This is important information for policy-making, as it can be used to consider trade-offs between the uncertainty in non- $\mathrm{CO}_{2}$ mitigation, possibly larger $\mathrm{CO}_{2}$ budgets, and a larger amount of committed warming at the multi-century scale due to larger cumulative $\mathrm{CO}_{2}$ emissions.

Applicability. Earlier we indicated that budgets that only take into account $\mathrm{CO}_{2}$-induced warming are scientifically best understood as - per definition - they do not depend on extra uncertainties associated with other forcings. However, at the same time, they are impractical and largely irrelevant for use in the real world, because of their obvious limitation of neglecting any contribution other than $\mathrm{CO}_{2}$. The other approaches that go beyond this $\mathrm{CO}_{2}$-only approach, might therefore be more practical. Using a $\mathrm{CO}_{2}$-only estimate for real-word decision-making would lead to an overestimation of the allowable carbon budget, that is, a very high risk of exceeding a given climate target when emitting that particular carbon budget.

The strength of TEBs is that they are easily comparable to TCREbased budgets for $\mathrm{CO}_{2}$-induced warming only. Hence the influence of non- $\mathrm{CO}_{2}$ forcing on the size of carbon budgets can be assessed. However, because of the limitations related to scenario selection (TEBs are derived from scenarios that fail in limiting warming to the temperature level of interest) and the timescales of the temperature response, TABs are preferred over TEBs. The strength of TABs lies exactly in their use of scenarios that represent our best understanding of how $\mathrm{CO}_{2}$ and other radiatively active species would evolve over time when $\mathrm{CO}_{2}$ emissions are stringently reduced.

\section{Conclusions}

Several possibilities are available to compute cumulative carbon budgets consistent with a particular temperature limit. We have shown that each of the carbon budget approaches has strengths but also comes with important limitations. The devil is in the detail here. The most scientifically robust number - the budget for $\mathrm{CO}_{2}$-induced warming - is also the least practical in the real world. Selecting budgets based on multi-gas emission scenarios that actually restrict warming to below a given temperature threshold, results in the lowest, but most relevant $\mathrm{CO}_{2}$ emission budgets in a real-world multi-gas setting. Any practical implementation of a carbon budget mitigation strategy would require parallel mitigation efforts for non- $\mathrm{CO}_{2}$ agents.

At the time of the IPCC AR5, no established methodologies were available to ensure easy comparability of carbon budget estimates across working groups. In hindsight and anticipating future assessments, three recommendations can be formulated. First, insofar as important topics can already be identified, coordinated model simulations, intercomparisons, and methods could be initiated at an early stage to ensure consistency and traceability. Second, consistency across - and collaboration and integration between - the IPCC working groups could be improved by setting up stronger ties between them. And third, IPCC reports should be clearer about the policy-applicability of the numbers they provide, without being policy prescriptive.

For limiting warming to below $2{ }^{\circ} \mathrm{C}$ relative to pre-industrial levels with greater than $66 \%$ probability, the remaining $\mathrm{CO}_{2}$ budget from 2015 onwards for $\mathrm{CO}_{2}$-induced warming only is $1,620 \mathrm{GtCO}_{2}$. The corresponding TAB budget would be $590-1,240 \mathrm{GtCO}_{2}$. The latter is equivalent to about 15 to 30 years of $\mathrm{CO}_{2}$ emission at current (2014) levels (about $40 \mathrm{GtCO}_{2} \mathrm{yr}^{-1}$, ref. 52). No matter which approach is taken, the $\mathrm{CO}_{2}$ budget for keeping warming to below $2{ }^{\circ} \mathrm{C}$ always implies stringent emission reductions over the coming decades and net zero $\mathrm{CO}_{2}$ emissions in the medium to long term. For policy-making in the context of the UNFCCC, we suggest using the 590-1240 $\mathrm{GtCO}_{2}$ estimate from 2015 onwards for a likely chance of limiting warming to below $2{ }^{\circ} \mathrm{C}$, as this is derived from an assessment of scenarios that effectively limit warming to below the $2{ }^{\circ} \mathrm{C}$ limit. Further efforts will be required to limit warming below $1.5^{\circ} \mathrm{C}$.

Received 10 April 2015; accepted 15 October 2015; published online 24 February 2016

\section{References}

1. United Nations Framework Convention on Climate Change (UN, 1992).

2. Adoption of the Paris Agreement FCC/CP/2015/L.9/Rev.1 (UNFCCC, 2015).

3. Andrew, H. M., Kirsten, Z., Reto, K. \& Matthews, H. D. Sensitivity of carbon budgets to permafrost carbon feedbacks and non- $\mathrm{CO}_{2}$ forcings. Environ. Res. Lett. 10, 125003 (2015).

4. Matthews, H. D. \& Caldeira, K. Stabilizing climate requires near-zero emissions. Geophys. Res. Lett. 35, L04705 (2008).

5. Matthews, H. D, Gillett, N. P., Stott, P. A. \& Zickfeld, K. The proportionality of global warming to cumulative carbon emissions. Nature 459, 829-832 (2009).

6. Zickfeld, K., Eby, M., Matthews, H. D. \& Weaver, A. J. Setting cumulative emissions targets to reduce the risk of dangerous climate change. Proc. Natl Acad. Sci. USA 106, 16129-16134 (2009). 
7. Meinshausen, M. et al. Greenhouse-gas emission targets for limiting global warming to $2{ }^{\circ} \mathrm{C}$. Nature 458, 1158-1162 (2009).

8. Allen, M. R. et al. Warming caused by cumulative carbon emissions towards the trillionth tonne. Nature 458, 1163-1166 (2009).

9. Gillett, N. P., Arora, V. K., Zickfeld, K., Marshall, S. J. \& Merryfield, W. J. Ongoing climate change following a complete cessation of carbon dioxide emissions. Nature Geosci. 4, 83-87 (2011).

10. Gillett, N. P., Arora, V. K., Matthews, D. \& Allen, M. R. Constraining the ratio of global warming to cumulative $\mathrm{CO}_{2}$ emissions using CMIP5 simulations. J. Clim. 26, 6844-6858 (2013).

11. Knutti, R. \& Rogelj, J. The legacy of our $\mathrm{CO}_{2}$ emissions: a clash of scientific facts, politics and ethics. Climatic Change 133, 361-373 (2015).

12. Smith, S. M. et al. Equivalence of greenhouse-gas emissions for peak temperature limits. Nature Clim. Change 2, 535-538 (2012).

13. Bowerman, N. H. A. et al. The role of short-lived climate pollutants in meeting temperature goals. Nature Clim. Change 3, 1021-1024 (2013).

14. Rogelj, J. et al. Disentangling the effects of $\mathrm{CO}_{2}$ and short-lived climate forcer mitigation. Proc. Natl Acad. Sci. USA 111, 16325-16330 (2014).

15. Collins, M. R. et al. in Climate Change 2013: The Physical Science Basis (eds Stocker, T. F. et al.) 1029-1136 (IPCC, Cambridge Univ. Press, 2013).

16. Frolicher, T. L., Winton, M. \& Sarmiento, J. L. Continued global warming after $\mathrm{CO}_{2}$ emissions stoppage. Nature Clim. Change 4, 40-44 (2014).

17. Mastrandrea, M. D. et al. Guidance Notes for Lead Authors of the IPCC Fifth Assessment Report on Consistent Treatment of Uncertainties 5 (IPCC, 2010).

18. Zickfel, K., Arora, V. K. \& Gillett, N. P. Is the climate response to $\mathrm{CO}_{2}$ emissions path dependent? Geophys. Res. Lett. 39, L05703 (2012).

19. Van Vuuren, D. P. et al. Temperature increase of 21 st century mitigation scenarios. Proc. Natl Acad. Sci. USA 105, 15258-15262 (2008).

20. Obersteiner, M. et al. Managing climate risk. Science 294, 786-787 (2001).

21. Azar, C. et al. The feasibility of low $\mathrm{CO}_{2}$ concentration targets and the role of bio-energy with carbon capture and storage (BECCS). Climatic Change 100, 195-202 (2010).

22. Tavoni, M. \& Socolow, R. Modeling meets science and technology: an introduction to a special issue on negative emissions. Climatic Change 118, 1-14 (2013).

23. Meinshausen, M., Raper, S. C. B. \& Wigley, T. M. L. Emulating coupled atmosphere-ocean and carbon cycle models with a simpler model, MAGICC6 - Part 1: Model description and calibration. Atmos. Chem. Phys. 11, 1417-1456 (2011).

24. Rogelj, J., Meinshausen, M. \& Knutti, R. Global warming under old and new scenarios using IPCC climate sensitivity range estimates. Nature Clim. Change 2, 248-253 (2012).

25. Matthews, H. D., Solomon, S. \& Pierrehumbert, R. Cumulative carbon as a policy framework for achieving climate stabilization. Phil. Trans. R. Soc. A 370, 4365-4379 (2012).

26. IPCC Summary for Policymakers in Climate Change 2013: The Physical Science Basis (eds Stocker, T. F. et al.) 1-29 (Cambridge Univ. Press, 2013).

27. Clarke, L. et al. International climate policy architectures: overview of the EMF 22 International Scenarios. Energy Econ. 31, S64-S81 (2009).

28. Riahi, K. et al. in Global Energy Assessment-Toward a Sustainable Future (eds Johansson, T. B., Patwardhan, A., Nakicenovic, N. \& Gomez-Echeverri, L.) 1203-1306 (Cambridge Univ. Press and IIASA, 2012).

29. Kriegler, E. et al. The role of technology for achieving climate policy objectives: overview of the EMF 27 study on global technology and climate policy strategies. Climatic Change 123, 353-367 (2014).

30. Moss, R. H. et al. The next generation of scenarios for climate change research and assessment. Nature 463, 747-756 (2010).

31. Van Vuuren, D. P. et al. The representative concentration pathways: an overview. Climatic Change 109, 5-31 (2011).

32. Taylor, K. E., Stouffer, R. J. \& Meehl, G. A. An Overview of CMIP5 and the Experiment Design. Bull. Am. Meteorol. Soc. 93, 485-498 (2011).

33. IPCC Summary for Policymakers in Climate Change 2014: Synthesis Report (eds Pachauri, R. K. et al.) 1-33 (Cambridge Univ. Press, 2014).

34. IPCC Summary for Policymakers in Climate Change 2014: Mitigation of Climate Change (eds Edenhofer, O. et al.) 1-33 (Cambridge Univ. Press, 2014).

35. Clarke, L. et al. in Climate Change 2014: Mitigation of Climate Change (eds Edenhofer, O. et al.) 413-450 (Cambridge Univ. Press, 2014).
36. Friedlingstein, P. et al. Persistent growth of $\mathrm{CO}_{2}$ emissions and implications for reaching climate targets. Nature Geosci. 7, 709-715 (2014)

37. Schaeffer, M. et al. Mid- and long-term climate projections for fragmented and delayed-action scenarios. Technol. Forecast. Soc. Change 90, 257-268 (2015).

38. Rogelj, J. et al. Energy system transformations for limiting end-of-century warming to below $1.5^{\circ} \mathrm{C}$. Nature Clim. Change 5, 519-527 (2015).

39. Riahi, K. et al. RCP 8.5 - A scenario of comparatively high greenhouse gas emissions. Climatic Change 109, 33-57 (2011).

40. Jones, C. et al. Twenty-first-century compatible $\mathrm{CO}_{2}$ emissions and airborne fraction simulated by CMIP5 earth system models under four representative concentration pathways. J. Clim. 26, 4398-4413 (2013)

41. Zickfeld, K. et al. Long-term climate change commitment and reversibility: an EMIC intercomparison. J. Clim. 26, 5782-5809 (2013).

42. Stocker, T. F. et al. in Climate Change 2013: The Physical Science Basis (eds Stocker, T. F. et al.) 33-115 (Cambridge Univ. Press, 2013).

43. Meinshausen, M., Wigley, T. M. L. \& Raper, S. C. B. Emulating atmosphereocean and carbon cycle models with a simpler model, MAGICC6 - Part 2: Applications. Atmos. Chem. Phys. 11, 1457-1471 (2011).

44. Rogelj, J., Meinshausen, M., Sedláček, J. \& Knutti, R. Implications of potentially lower climate sensitivity on climate projections and policy. Environ. Res. Lett. 9, 031003 (2014).

45. Smith, L. A. \& Stern, N. Uncertainty in science and its role in climate policy. Phil. Trans. R. Soc. A 369, 4818-4841 (2011).

46. Ricke, K. L. \& Caldeira, K. Maximum warming occurs about one decade after a carbon dioxide emission. Environ. Res. Lett. 9, 124002 (2014).

47. Zickfeld, K. \& Herrington, T. The time lag between a carbon dioxide emission and maximum warming increases with the size of the emission. Environ. Res. Lett. 10, 031001 (2015).

48. Rogelj, J. et al. Air-pollution emission ranges consistent with the representative concentration pathways. Nature Clim. Change 4, 446-450 (2014).

49. Gernaat, D. E. H. J. et al. Understanding the contribution of non-carbon dioxide gases in deep mitigation scenarios. Glob. Environ. Change 33, 142-153 (2015)

50. Rogelj, J. et al. Mitigation choices impact carbon budget size compatible with low temperature goals. Environ. Res. Lett. 10, 075003 (2015).

51. Rogelj, J., Meinshausen, M., Schaeffer, M., Knutti, R. \& Riahi, K. Impact of short-lived non- $\mathrm{CO}_{2}$ mitigation on carbon budgets for stabilizing global warming. Environ. Res. Lett. 10, 075001 (2015).

52. Le Quéré, C. et al. Global carbon budget 2014. Earth Syst. Sci. Data Discuss 7, 521-610 (2014).

53. Myhre, G. et al. in Climate Change 2013: The Physical Science Basis (eds Stocker, T. F. et al.) 659-740 (IPCC, Cambridge Univ. Press, 2013).

54. Boucher, O. \& Reddy, M. S. Climate trade-off between black carbon and carbon dioxide emissions. Energy Policy 36, 193-200 (2008).

55. Brohan, P., Kennedy, J. J., Harris, I., Tett, S. F. B. \& Jones, P. D. Uncertainty estimates in regional and global observed temperature changes: a new data set from 1850. J. Geophys. Res.-Atmos. 111, D12106 (2006).

\section{Acknowledgements}

We acknowledge the work by IAM modellers that contributed to the IPCC AR5 Scenario Database and the climate modelling teams contributing to CMIP5. We thank IIASA for hosting the IPCC AR5 Scenario Database, and M. Meinshausen for detailed comments and feedback on the manuscript.

\section{Author contributions}

All authors contributed to parts of the underlying research during the writing process of the IPCC AR5. J.R. coordinated the conception and the writing of the paper. J.R. carried out the research with significant contributions from M.S., and developed the TEB and $\mathrm{TAB}$ conceptual framework. J.R. produced the figures and wrote the first draft of the manuscript. All authors contributed to interpreting and discussing the results, and writing the paper.

\section{Additional information}

Reprints and permissions information is available online at www.nature.com/reprints. Correspondence should be addressed to J.R.

\section{Competing financial interests}

The authors declare no competing financial interests. 